\title{
A JORNADA DA NOVA ETICIDADE AMBIENTAL ${ }^{1}$
}

\section{Magno Federici Gomes ${ }^{2}$ Humberto Gomes Macedo ${ }^{3}$}

RESUMO: Este estudo tem como escopo trabalhar o fundamento da eticidade ambiental a partir da obra de Naves e Reis (2019), e a "ética ambiental" por Lourenço (2019). Será abordado ainda, como o imperativo categórico em Kant foi fundamental na consolidação da dignidade humana e qual o seu novo papel. Foram utilizados a pesquisa bibliográfica, raciocínio dedutivo, e método teórico-jurídico. Em conclusão, evidencia-se que há necessidade de uma mudança do paradigma focado no ser humano como epicentro do Direito, o que torna a eticidade ambiental uma nova linha de reflexão a moldar os estudos sobre a importância do ser humano no planeta.

Palavras-chave: Ética ambiental; Dignidade humana; Proteção ecológica.

\section{THE JOURNEY OF THE NEW ENVIRONMENTAL ETHICS}

ABSTRACT: This study aims to work on the foundation of environmental ethics from the work of Naves e Reis (2019) and the "environmental ethics" by Lourenço (2019). It will also be discussed, how the categorical imperative in Kant was fundamental in the consolidation of human dignity. Bibliographic research, deductive reasoning and theoretical-legal method were used. In conclusion, it is evident that there is a need for a change in the paradigm focused on the human being as the epicenter of Law, which makes environmental ethics a new line of reflection about the importance of human beings on the planet.

Keywords: Environmental ethics"; Human dignity; Ecological protection.

\section{INTRODUÇÃO}

\footnotetext{
${ }^{1}$ Trabalho financiado pelo Projeto Edital no 03/2019 de Incentivo à Pesquisa da Escola Superior Dom Helder Câmara, resultante dos Grupos de Pesquisas (CNPQ): Responsabilidade Civil e Processo Ambiental (RECIPRO), NEGESP, Metamorfose Jurídica e CEDIS (FCT-PT).

${ }^{2}$ Estágio Pós-doutoral em Direito Público e Educação pela Universidade Nova de Lisboa-Portugal (Bolsa CAPES/BEX 3642/07-0). Estágios Pós-doutorais em Direito Civil e Processual Civil, Doutor em Direito e Mestre em Direito Processual, pela Universidad de Deusto-Espanha (Bolsa da Cátedra UNESCO e do Gobierno Vasco-Espanha). Mestre em Educação pela PUC Minas. Coordenador e Professor do Doutorado e Mestrado Acadêmico em Direito Ambiental e Desenvolvimento Sustentável na Escola Superior Dom Helder Câmara. Professor Titular licenciado da Faculdade de Direito Arnaldo Janssen. Advogado Sócio do Escritório Moraes \& Federici Advocacia Associada. Líder do Grupo de Pesquisa: Responsabilidade Civil e Processo Ambiental (RECIPRO)/CNPQ-BRA e integrante dos grupos: Centro de Investigação \& Desenvolvimento sobre Direito e Sociedade (CEDIS)/FCT-PT, Núcleo de Estudos sobre Gestão de Políticas Públicas (NEGESP)/CNPQ-BRA e Metamorfose Jurídica/CNPQ-BRA. ORCID: http://orcid.org/0000-0002-4711-5310. Currículo Lattes: http://lattes.cnpq.br/1638327245727283. E-mail: magnofederici@ gmail.com

${ }^{3}$ Professor de Direito Civil e Doutorando em Direito Ambiental na Escola Superior Dom Hélder Câmara. Advogado autárquico do Estado de Minas Gerais. ORCID: http://orcid.org/0000-0001-8840-3362. Currículo Lattes: http://lattes.cnpq.br/2965597903526871. E-mail: hgmacedo@hotmail.com.
} 
Com a evidência de inúmeros desastres ambientais, da mudança climática, dos incêndios exacerbados, da compulsão ao consumo, da pandemia, dentre outros temíveis eventos, há necessidade de mudança do paradigma filosófico-jurídico que não mais deve considerar o ser humano como o fim único e absoluto dos ditames normativos sociais.

Nesse viés, será feita uma incursão pela filosofia kantiana, com enfoque em como o Imperativo Categórico foi importante para a consolidação da dignidade da pessoa humana, e qual a leitura atual sobre a teoria em face da preocupação ecológica e das mudanças de perspectiva acerca da importância do ser humano no planeta e na história.

Enfim: qual o papel filosófico e jurídico do ser humano no atual momento de crise ambiental global? Continua "fim" e epicentro do Direito ou deve passar a ser "meio" para a proteção ecológica?

Assim, com base nas obras de Naves e Reis (2019) e Lourenço (2019) - que fazem um estudo sobre as principais correntes filosófico-ambientais - o objetivo desta pesquisa é efetivar uma releitura dessa linha moderna (de Kant) em face de nova eticidade ambiental.

A pesquisa se justifica, desta feita, no sentido de que os estudos devem evoluir para se readaptar aos fatos que se apresentam ao longo da história, com ênfase na busca por entendimentos que moldem a proteção ecológica e o novo papel do homem enquanto ser do meio (e não fim), neste contexto.

Para tanto, a metodologia utilizada foi a pesquisa exploratória apoiada em levantamento bibliográfico e através de método hipotético-dedutivo, já que baseada em estudo meramente doutrinário.

Assim, o primeiro capítulo buscará explicar o Imperativo Categórico de Kant com ênfase na autonomia da vontade e na razão humanas pelo eminente filósofo. O segundo, apresentará a linha da eticidade ambiental pelos outros autores supra citados como marco teórico. No terceiro, se apontará a conexão entre a dignidade humana tradicionalmente estudada e a nova eticidade ambiental proposta; partindo-se para a conclusão acerca da importância e necessidade de estudos, pesquisas, e aplicação de uma nova filosofia voltada para a integração entre o homem e a natureza no mesmo patamar de importância e objeto.

\section{A ÉTICA, O IMPERATIVO CATEGÓRICO E A AUTONOMIA EM KANT}


O filósofo Immanuel Kant (1724-1804) é um dos pensadores mais referenciados no que tange à filosofia moderna ocidental. Suas ideias fundamentam a estrutura do pensamento sobre a dignidade humana e o próprio papel do homem na história.

O pensamento ético de Kant é fruto, em grande parte, da rejeição que ele propõe à diversas teorias historicamente influentes, principalmente a de que a base ou fonte da moral ou eticidade ${ }^{4}$ seriam aquelas vindas da vontade divina.

Enfrentando a moral empírica e a base medieval da fonte ética na vontade de Deus, Kant busca defender que não se pode conceber um princípio ético supremo como algo que é imposto por uma autoridade externa, no caso, a da inspiração celestial, mas que a busca para o fundamento da moral deve estar no homem.

O filósofo considera que os princípios éticos devam ser universais e necessários, no sentido que são aplicáveis a todos e em todas as circunstâncias máximas possíveis, de acordo com o primado da razão e vontade humanas. Eis, grosso modo, o seu Imperativo Categórico, pois o "imperativo" tem sentido de imposição ou ordem, e "categórico" tem sentido de que deve ser aplicado de forma incondicional, guiado na vontade racional, e não adaptado ou conforme determinado objetivo ou finalidade.

É expresso tal princípio através de algumas “fórmulas”, aqui ressaltadas nas três principais:

(i) Age apenas segundo uma máxima tal que possas ao mesmo tempo querer que ela se torne lei universal (...) (ii) Age de tal maneira que uses a humanidade, tanto na tua pessoa como na de qualquer outro, sempre e simultaneamente como fim e nunca simplesmente como meio (...) (iii) A ideia da vontade de todo o ser racional concebida como vontade legisladora universal (KANT, 2011, p. 62 e77).

Nesse aspecto, o agir ético do ser humano é inspirado por uma conduta que possa ser convertida em uma norma universal, e não por escolhas externas ou alheias. Ensina Kant:

Quando penso um imperativo hipotético em geral, não sei de antemão o que ele poderá conter. Só o saberei quando a condição me seja dada. Mas se pensar um imperativo categórico, então sei imediatamente o que é que ele contém. Porque, não contendo o imperativo, além da lei, senão a necessidade da máxima que manda conformar-se esta lei, e não contendo a lei nenhuma condição que a limite, nada mais resta senão a universalidade de uma lei em geral à qual a máxima de ação deve ser conforme, conformidade essa que só o imperativo nos representa propriamente como necessária. O imperativo categórico é portanto só um único, que é este: Age

\footnotetext{
${ }^{4}$ Ética e moralidade (moral) são aqui tratadas de forma indistinta.
} 
apenas segundo uma máxima tal que possas ao mesmo tempo querer que ela se torne lei universal (KANT, 2011, p. 61-62).

Além disso, o filósofo traz como exemplo de uma atitude racional e moralmente devida a explicação abaixo colacionada, o que chama à tona para ações eticamente corretas em seu imperativo categórico universal:

\begin{abstract}
Uma terceira pessoa encontra em si um talento natural que, cultivado em certa medida, poderia fazer dela um homem útil sob vários aspectos. Mas encontra-se em circunstâncias cómodas e prefere ceder ao prazer a esforçar-se por alargar e melhorar as suas felizes disposições naturais. Mas está em condições de poder perguntar ainda a si mesmo se, além da concordância que a sua máxima do desleixo dos seus dons naturais tem com a sua tendência para o gozo, ela concorda também com aquilo que se chama dever. E então vê que na verdade uma natureza com uma tal lei universal poderia ainda subsistir, mesmo que o homem (como os habitantes dos mares do Sul) deixasse enferrujar o seu talento e cuidasse apenas de empregar a sua vida na ociosidade, no prazer, na propagação da espécie, numa palavra - no gozo; mas não pode querer que isto se transforme em lei universal da natureza ou que exista dentro de nós por instinto natural. Pois como ser racional quer ele necessariamente que todas as suas faculdades se desenvolvam, porque lhe foram dadas e lhe servem para toda a sorte de fins possíveis (KANT, 2011, p. 64-65) ${ }^{5}$.
\end{abstract}

Os seres humanos são configurados como um fim em si mesmos e pautados num valor absoluto que é a sua dignidade. Foi muito importante, assim, para trazer elementos primários à dignidade humana como o valor intrínseco de todos os seres humanos, a laicização no sentido de que a conduta e razão humanas não são pautadas pela vontade divina, ou pelos costumes dos povos, e sim pela autonomia de cada indivíduo, valorando o homem.

Nessa esteira Barroso, ao tratar da influência do pensamento kantiano sobre à dignidade, ressalta acerca da importância da lei moral guiada pela racionalidade humana: “A ética Kantiana é inteiramente baseada nas noções de razão e dever, na capacidade do indivíduo dominar suas paixões e interesses próprios e descobrir, dentro de si mesmo, a lei moral que deve orientar sua conduta" (BARROSO, 2016, p. 68).

Ele também explica novamente sobre o Imperativo Categórico, destacando a "fórmula genérica" capaz de explicar as atitudes morais ou éticas:

Baseado nos gregos antigos, Kant divide a filosofia em três partes: lógica, que é a filosofia formal aplicada a todo o pensamento; física, que lida com as leis da

\footnotetext{
${ }^{5} \mathrm{O}$ exemplo pode, até mesmo, conclamar para a necessidade ações coletivas em prol do todo, do mundo, do social, dando ensejo à proteção ecológica, e não meramente egoístas ou individualistas, delineadas nos próximos capítulos.
} 
natureza e descreve o mundo como ele é; e ética, que tem como objeto a vontade humana e prescreve o que ela deve ser. A ética é o domínio da lei moral, composta por comandos que regem a vontade que está em conformidade com a razão. Tais comandos expressam um dever-ser, um imperativo, que pode ser hipotético ou categórico. $\mathrm{O}$ imperativo hipotético identifica uma ação que é boa como um meio para alcançar um fim. O imperativo categórico, por sua vez, corresponde a uma ação que é boa em si mesma, independentemente do fato de servir a um determinado fim. Ele é um padrão de racionalidade e representa o que é objetivamente necessário em uma vontade que esteja em conformidade com a razão. Esse imperativo categórico, ou imperativo da moralidade, foi denunciado por Kant em uma famosa proposição sintética: "Age de tal modo que a máxima da tua vontade (i.e., o princípio que a inspira e move) possa se transformar em uma lei universal". Note-se que em lugar de apresentar um catálogo de virtudes específicas, uma lista do que fazer e do que não fazer, Kant concebeu uma fórmula capaz de determinar a ação ética (BARROSO, 2016, p. 70).

Dessa forma, fica destacada a importância da humanidade como fim da própria estruturação filosófica, social e racional, no sentido de que a construção histórica não deve se utilizar do ser humano como meio em situações que podem desconstituir a própria essência do "ser humano", mas no sentido de ser o fim ou o escopo dele e por ele próprio.

Daí, mais um ponto de mutação em se erigir a proteção ecológica como o fim máximo e último, no sentido de se configurar a natureza ou ao lado da humanidade - que lhe protege e defende no próprio sentido de dignidade humana que se amplia - ou mesmo no sentido de se colocar a preocupação ambiental como o escopo final de todos os esforços filosóficos e sociais. Ressalta:

\begin{abstract}
Embora Kant afirme que há um único imperativo categórico, reproduzido acima, ele apresenta três diferentes formulações dele. O primeiro é conhecido como fórmula da lei da natureza, que declara: "Aja como se a máxima que fundamentou sua ação deve-se tornar, pela sua própria vontade, uma lei universal da natureza". A segunda formulação é chamada de fórmula da humanidade: "Age de modo a utilizar a humanidade, seja em relação à tua própria pessoa ou a qualquer outra, sempre e todo o tempo como um fim, e nunca meramente como um meio". A terceira é a fórmula da autonomia: "E isso é feito na presente fórmula do princípio, a saber, a ideia da vontade de cada ser racional como a vontade formuladora da lei universal". A primeira e a terceira fórmulas são bastante próximas, exceto pelo fato de o foco mudar da obediência à lei universal para a sua formulação. A segunda fórmula, com uma aspecto humanista mais destacado e uma ênfase no respeito pelas pessoas, parece oferecer uma perspectiva diferente. Kant, contudo, afirmou que todas as formulações eram equivalentes, indicando, provavelmente, que elas levavam aos mesmos deveres (BARROSO, 2016, p.70).
\end{abstract}

A dignidade como fim é fundamentada, justamente, pela autonomia humana, o que mais uma vez colabora no sentido de se verificar a especialidade e importância do homem, ser único e capaz de agir com racionalidade apta a entender o mundo como fenômeno. 
A dignidade, por sua vez, dentro da visão kantiana, tem por fundamento a autonomia. Em um mundo no qual todos pautem a sua conduta pelo imperativo categórico - no "reino dos fins" -, como escreveu -, tudo tem um preço ou uma dignidade. As coisas que têm preço podem ser substituídas por outras equivalentes. Mas quando uma coisa está acima de todo preço e não pode ser substituída por outra equivalente, ela tem dignidade. Assim é a natureza singular do ser humano. Portanto, as coisas têm um preço de mercado, mas as pessoas têm um valor absoluto chamado de dignidade. Como consequência, cada ser racional e cada pessoa existe como um fim em si mesmo, e não como um meio para o uso discricionário de uma vontade externa. E essa é, como visto, a segunda formulação do imperativo categórico (BARROSO, 2016, p. 70-71).

Dessa forma, Kant vai descobrir que diferentemente do mundo natural que é regido por leis necessárias, o ser humano tem a capacidade de autonomia (auto nomos), de guiar as suas ações por uma lei que pode ser escolhida por ele mesmo e não por um agente externo a ele. No mundo natural, se há ação, a reação é necessária. Como o ser humano é um ser de razão, de vontade, de autonomia, ele pode escolher reagir diferente das leis necessárias, própria dos seres naturais: ao invés de dar soco, por exemplo, em quem o agride, ele pode escolher dialogar.

Segundo o pensador, o que há de especial no homem, e o que o difere dos outros seres seria a vontade. E seguindo-a (a vontade, não aos seus interesses imediatos e as suas inclinações sensíveis) o homem não necessariamente sente felicidade, no entanto, é justamente pela capacidade do ser humano agir para além de seus interesses, que ele é um ser de dignidade. Para o próprio filósofo:

[...] mas o sujeito de todos os fins é (conforme o segundo princípio) todo o ser racional como fim em si mesmo: daqui resulta o terceiro princípio prático da vontade coo condição suprema da concordância desta vontade com a razão prática universal, quer dizer a ideia da vontade de todo o ser racional concebida como vontade legisladora universal. Segundo este princípio são rejeitadas todas as máximas que não possam subsistir juntamente com a própria legislação universal da vontade. A vontade não está simplesmente submetida à lei, mas sim submetida de tal maneira que tem de ser considerada também como legisladora ela mesma, e exatamente por isso e só então submetida à lei (de que ela se pode olhar como autora) (KANT, 2011, p.77).

Já para Naves e Reis, Kant (re)coloca o homem no centro da moralidade, "pois se autolegisla através de uma lei dada por sua própria vontade", o que, inclusive, ilustraria a "autonomia da vontade humana" (NAVES; REIS, 2019, p. 135). Para os autores, essa autonomia da vontade humana gera a terceira fórmula do imperativo categórico. 
Para Kant, pelo fato de todo homem racional ter esta lei em si, eles fazem parte do reino dos fins, que é a ligação entre todos os homens através de uma lei universal. A autonomia da vontade humana gera uma terceira fórmula do imperativo categórico: "[...] a vontade possa, mediante sua máxima, se considerar ao mesmo tempo a si mesma como legislando universalmente" (NAVES; REIS, 2019, p. 135).

As outras duas seriam "age como se a máxima de tua ação devesse se tornar por tua vontade uma lei universal da natureza" (KANT, 2011, p. 62) e "age de tal maneira que tomes a humanidade, tanto em tua pessoa, quanto na pessoa de qualquer outro, sempre ao mesmo tempo como fim, nunca meramente como meio" (KANT, 2011, p. 77). Complementam:

\begin{abstract}
O imperativo categórico será, pois, compreendido como um princípio a priori próprio da natureza humana, que vale para todos os seres racionais, que possuem vontade, compreendida como uma faculdade capaz de se autodeterminar e agir conforme a lei. Isto significa que o homem é um ser autônomo. Para Kant, é um argumento para se tornar o homem como um fim em si mesmo, pois é o fundamento da lei. Assim, um indivíduo jamais pode ser tomado como um meio (instrumento) para os outros. Os demais seres, moralmente falando, são condicionados ao contexto, o homem, por outro lado, deve ser tomado de maneira absoluta (NAVES; REIS, 2019, p. 134-135).
\end{abstract}

Importante é que Naves e Reis (2019, p. 134), ratificam que o "fundamento da lei”, criada pelo próprio homem, é a justificativa para que ele se torne como um fim em si mesmo. Dessa maneira, um ser humano não pode ser utilizado como um instrumento ao uso dos demais. Seriam os demais seres vivos, no contexto ético e filosófico, apenas vinculados (acessórios) ao contexto (principal) que é o ser humano tomado de forma total e absoluta, na analogia à fórmula "o acessório segue o principal".

Kant, dessa feita, foi fundamental para ressaltar e ratificar a potencialidade da razão humana tanto como guia de suas ações éticas, como para o fim de suas ações em prol de sua própria dignidade.

\title{
2 EVOLUÇÃO DA ETICIDADE AMBIENTAL E SUA ADERÊNCIA À FILOSOFIA DE KANT
}

Nesse destaque acerca da importância da filosofia de Kant para a estruturação da humanidade como fim, e da própria essência do "ser humano", é que se demonstra importante a evolução e a continuidade dos estudos sobre o novo papel do homem - e da humanidade como um todo - na premissa atual da necessidade premente de proteção ecológica. 
O homem "sendo um fim" é um alargamento da razão humana indubitavelmente, mas ele não vive sem a natureza. Ele não é só racionalidade. Então, necessário ampliar o entendimento desse escopo humano na Terra, como um alargamento do "reino dos fins", proposto por Kant. Ou seja, abarcar a condição de homem não apenas na racionalidade como queria a modernidade, mas a natureza também com elemento desse escopo.

Como dito, para o homem ser verdadeiramente o fim, ele deve proteger a natureza. $\mathrm{O}$ homem, nem a natureza, podem ser meios de exploração, mas meios para se alcançar a proteção ecológica e de potencializar a própria dignidade.

Assim, o desafio atual deve ser refletido no sentido da reconstrução do próprio direito humano e de sua dignidade. Ou seja, se tornou necessária uma releitura que recoloque o papel do homem não mais como fim absoluto - o que poderia justificar ações danosas à natureza ou, pelo menos, numa releitura da dignidade humana que instaure a proteção ecológica a seu lado, junto, no mesmo degrau ou patamar. Desse modo:

Tendo como premissa o caráter normativo e, portanto, vinculante, da dignidade da pessoa humana, a ela é conferido um duplo papel no sistema, pois além de seu enquadramento na condição de norma fundamental, sendo um conteúdo autônomo de direitos, o princípio da dignidade da pessoa humana também funciona como fonte de direitos, garantias e deveres fundamentais capaz de nortear os sentidos desses direitos, justificar o reconhecimento de novos direitos, bem como ser verdadeiro critério de ponderação de sentido na implicação recíproca entre os diversos direitos fundamentais com ele relacionados (COELHO; MELLO, 2011, p. 17).

É a busca por um pensamento teórico-reflexivo que reflita sobre o atual sentido do princípio da dignidade da pessoa humana que pede para ser ético e coerente, a proteção, o respeito, e a abrangência dos estudos e ações que integrem também as questões da natureza extra humana.

\subsection{A Bioética ambiental}

O marco teórico para a Eticidade Ambiental nesta pesquisa é formado, principalmente, pelas obras Naves e Reis (2019) e Lourenço (2019). 
No primeiro livro, Naves e Reis (2019) enumeram os antecedentes históricos da Bioética, desde Hipócrates na Grécia Antiga ${ }^{6}$, passando por "experimentações com seres humanos na Segunda Guerra Mundial e Código de Nuremberg”, o Caso Tuskegee, o Desastre de Minamata e a Primavera Silenciosa de Rachel Carson (2011), até o surgimento da Bioética e da Bioética Global (NAVES; REIS, 2019, p. 3-9).

Além disso, explicam acerca do conceito e significado da bioética como uma "ética ampla" destinada a abranger uma análise e preocupação com todos os seres vivos, assim aduzindo.

Logo após, no Capítulo 4, apresentam a bioética como "Espaço Transdisciplinar e Reflexão e tomada de Decisão", apontando o espaço importante que a bioética apresenta ao se configurar como uma disciplina multidisciplinar e que avalia aspectos "não humanos" em sua chave de leitura.

Indicam a divisão entre macrobioética ${ }^{7}$ e microbioética $^{8}$ para, finalmente, conceituarem "Biocentrismo ${ }^{9}$ versus Antropocentrismo ${ }^{10}$ " como uma dicotomia do estudo da macrobioética (NAVES; REIS, 2019, p. 16).

Sobre o antropocentrismo, esclarecem, e também classificam, as duas espécies entre clássico e mitigado, como:

\begin{abstract}
O antropocentrismo clássico não impõe deveres morais ao homem em relação ao meio ambiente. Seus deveres morais estão voltados a si mesmo e seus semelhantes. Já o antropocentrismo mitigado reconhece a existência de deveres humanos para com o meio ambiente, ainda que indiretos ou voltados à proteção de gerações futuras. Pelo antropocentrismo mitigado, a intervenção humana deve se fazer por meio de critérios que definam limites e responsabilidades. $\mathrm{O}$ foco continua sendo o homem, já que a natureza deve receber proteção em razão de sua importância para o homem e suas necessidades, mas o reconhecimento de que isso deve se fazer dentro de certo equilíbrio (NAVES; REIS, 2019, p. 18).
\end{abstract}

Sobre o biocentrismo, também indicam três subdivisões entre o biocentrismo mitigado, o ecocentrismo e a ecologia profunda da seguinte maneira:

\footnotetext{
6 "Na Grécia Antiga, as obras de Hipócrates (460-377- a.C.) traziam disposições sobre a Bioética. [...] Do Corpus Hippocratium também se confeccionou o princípio primum non nocere, extraído da recomendação de que o médico deve criar o hábito de auxiliar ou, ao menos, não causar danos" (NAVES; REIS, 2019, p. 3).

${ }^{7}$ A macrobioética "aborda as questões ecossistêmicas, como a preocupação com o meio ambiente, com o uso da informação como poder ou com a globalização. Daí vem sua conexão com as questões do biopoder e da biopolítica" (NAVES; REIS, 2019, p. 16).

8 “A Microbioética, por sua vez, analisa questões mais pontuais, como problemas trazidos pela biotecnologia e pelos avanços na área da saúde" (NAVES; REIS, 2019, p. 16).

9 "Biocentrismo mitigado, Ecocentrismo e Ecologia Profunda" (NAVES; REIS, 2019, p. 18).

10 “Antropocentrismo clássico e Atropocentrismo mitigado" (NAVES; REIS, 2019, p. 18).
} 
Para o Biocentrismo, de forma geral, a proteção do meio ambiente se realizaria de forma a beneficiar todos os indivíduos portadores de vida ou toda a natureza, sem estabelecer uma diferenciação entre homens e o meio ambiente. $\mathrm{O}$ valor da vida, em toda as suas dimensões, constitui-se como o principal critério classificatório, ampliando o espectro de seres moralmente consideráveis. Nele, podem-se visualizar três sub-categorias: o Biocentrismo mitigado, o Ecocentrismo e a Ecologia profunda (NAVES; REIS, 2019, p. 19).

Sobre o biocentrismo mitigado, tal conceito é fundamentado nos estudos de Peter Singer e Paul Taylor. Destacam na obra de Taylor (2011) o apreço pela importância de todos os seres vivos no sistema vital do planeta, além da citação de quatro princípios que orientam a ideia do autor de "Respect of Nature", como: (i) não maleficência, (ii) a não interferência, (iii) a fidelidade e (iv) a justiça retributiva. Ao citarem Peter Singer, identificam o surgimento da senciência animal, da sua importância e análise, além da obrigação de se pensar a igualdade entre os seres (humanos e outros).

Já o ecocentrismo é tratado como o movimento de maior antagonismo ao antropocentrismo e que busca a consideração moral de todos os seres de forma holística e em uma comunidade ecológica não apenas humana na seguinte concepção:

O ecocentrismo é um movimento de maior oposição ao antropocentrismo. Sua característica maior é ser holístico. Ele parte de conhecimentos da ecologia para se chegar ao estabelecimento de normas para o meio ambiente. Defende-se que a consideração moral não deve se voltar para um ser específico, um animal ou um vegetal, mas aos conjuntos sistêmicos, isto é, aos ecossistemas, à biosfera etc (NAVES; REIS, 2019, p. 21).

Em suma, os autores organizam os movimentos entre biocentrismo (biocentrismo mitigado, o ecocentrismo e a ecologia profunda) e o antropocentrismo (antropocentrismo Clássico e mitigado), até encerrarem e partirem para a conclusão com a "Crítica à Metafísica dos "Ismos", em que reforçam a necessidade intelectual de se focar no fundamento das ideias e obras, e não no dualismo classificatório, "generalizante", ou dualista de "isso ou aquilo", como se o antagonismo de posições fosse suficiente à academia para se encontrar uma tese "vencedora" no debate. Para os autores:

Assim, o Direito não será propriamente antropocêntrico ou biocêntrico, pois as complexas relações humanas com o meio ambiente ou a regulação jurídica que o ser humano empreende não é nenhum deles. Porque não contém um valor fixo, até porque a lei não é nada sem interpretação. O Direito é, sobretudo, um discurso, uma argumentação sobre uma certa semântica da lei. Não há um sentido metafísico para 
o Direito. Todo sentido é construído e localizado historicamente. E, por isso mesmo, influenciado pelos valores. É importante ler tais valores à luz de uma Bioética ampla. A compreensão é histórica e só pode se realizar na história. O que significa que a história conduz e limita toda atribuição de sentido. Sob a ótica filosófica, concepções antropocêntricas e/ou biocêntricas, se não precedidas de reflexão, serão sempre eventuais e efêmeras, podendo ser modificadas à luz de um interesse qualquer (NAVES; REIS, 2019, p. 24) ${ }^{11}$.

Por fim, no prelúdio ao estudo da ética filosófica no capítulo da "Defesa de Novos Sujeitos Morais", sugerem que "a nova Ética preocupa-se com “o ser”, e não somente com o ser humano" (NAVES; REIS, 2019, p. 25), o que, inclusive, sugeriria um novo imperativo categórico em direção ao futuro como é o objeto deste texto: "Portanto, enquanto a investigação ontológica extra-humana puder levar-nos para a teoria universal do ser e da vida, ela não se terá afastado realmente da ética, mas terá ido atrás de sua fundamentação possível" (NAVES; REIS, 2019, p. 24-26).

Assim, indicam que a bioética não se reduz à biomedicina e, sim, a uma teoria ética mais ampla que, além de pragmática e de "ética de ação" (NAVES, REIS, 2019, p. 15), abrange o estudo interdisciplinar da geociências, ciências biológicas, humanas e sobre os impactos sobre os ecossistemas, o que, pode-se considerar como uma verdadeira ética ambiental "lato sensu".

A abordagem e o alcance da bioética ambiental baseiam-se no enquadramento da atenção da vida como um todo: vida humana e natural. Na referida obra, os seus discursos superam a bioética clássica, visto que rompe com o dualismo "homem/natureza", na abordagem tradicional de uma bioética de enfoque apenas biomédico.

Nessa linha, ressaltam a importância do diálogo entre a ética filosófica clássica e a bioética no Direito, no sentido de que a reflexão moral, por mais humana que seja em sua essência, deve se aproximar dada vez mais da integração dos demais seres como referenciais de importância no seu escopo do seu discurso.

\subsection{A Ética ambiental}

11 “Conclui-se, ainda, que o argumento de que toda ética é antropocêntrica porque realizada por homens é falho. A Bioética parte do princípio antrópico, isto é, da constatação de que o desafio ambiental passa sempre pelo ser humano e suas considerações morais. É, pois, antrópica, mas não necessariamente antropocêntrica. No entanto isso não significa que, do outro lado, não possam figurar outros seres vivos como atores morais ou referenciais de moralidade" (NAVES; REIS, 2019, p. 26). 
Já a obra de Lourenço (2019) inicia, explicando, que utiliza a terminologia "ética ambiental" por questão de praticidade ao leitor, mas chamando a atenção para a ressalva acerca da utilização do termo "ambiental” e não "ecológico" ("ética ecológica”), o que poderia induzir a um entendimento antropocêntrico do termo (LOURENÇO, 2019, p. 34).

Interessante ainda que na mesma linha da crítica aos "ismos" perpetrada por Naves e Reis (2019), o autor busca encerrar a problemática que o dualismo ou antagonismo de termos e ideias pode gerar, buscando, dessa forma, agregar e conjugar entendimentos ao invés de dispersá-los. Assim:

\begin{abstract}
Essas dicotomias ou cosmovisões binárias se prestam a demarcar identidades por oposição. Por vezes, também são ventiladas na forma dicotômica: razão-e-emoção, natureza-cultura, civilização-barbárie, mente-corpo, sujeito-objeto, interno-externo, homem-mulher, material-espiritual, homem-animal, entre outras. A distinção que fraciona o espaço do natural e do artificial suscita uma série de outras questões. A principal delas talvez seja a de que se parte de uma pressuposição de que o homem está deslocado, apartado hierarquicamente da natureza, daí o porquê de sua intervenção produzir algo que supostamente não é natural, que não é dado, mas, ao contrário, processado, manufaturado, produzido e obtido por meio da técnica (LOURENÇO, 2019, p. 31-32).
\end{abstract}

Feitos os apontamentos acerca da terminologia e linha do trabalho, o autor apresenta como correntes da ética ambiental: o antropocentrismo no capítulo 1; no capítulo 2, o biocentrismo (dividido em biocentrismo de tipo igualitário, não igualitário e o biocentrismo mitigado ou animalismo); e as posições ecocêntricas no capítulo 3, divididas em ética da terra e ecologia profunda (“deep ecology”).

A posição antropocêntrica é tratada como "posição ambientalista tradicional: sustentabilidade e antropocentrismo", que tem como escopo básico o atendimento aos interesses puramente humanos (LOURENÇO, 2019, p. 51), e que também é dividida entre (i) antropocentrismo forte ${ }^{12}$ e (ii) fraco ou moderado ${ }^{13}$.

\footnotetext{
12 "A posição centrada no valor exclusivo do homem, denominada de antropocentrismo em sentido forte (clássico, extremado ou radical), sustenta que somente o homem possui valor próprio (antropocentrismo em sentido normativo), não havendo qualquer limite direto na utilização da natureza, colocada à sua disposição para satisfazer suas necessidades (antropocentrismo teleológico)" (LOURENÇO, 2019, p. 52-53).

13 "O antropocentrismo em sentido moderado (ou fraco), embora também afirme a elevação moral do homem frente aos demais entes, colocaria alguns limites à livre utilização do mundo natural, tendo em vista aspectos relacionados aos projetos humanos, como é o caso das preocupações ambientais" (LOURENÇO, 2019, p. 54).
} 
Disserta sobre a inconsistência e fragilidade do termo "sustentabilidade" 14 , e conclui sobre a insuficiência do modelo antropocêntrico como modelo de ética a ser aplicado à natureza, pois "o antropocentrismo, do ponto de vista de uma proposta de ética aplicada à natureza, mostra-se insuficiente no sentido de traduzir uma ética normativa minimamente sustentável” (LOURENÇO, 2019, p. 75).

Já o biocentrismo, tem como principal postulação a de que "todos os organismos vivos possuem valor intrínseco, são fins em si mesmo" (LOURENÇO, 2019, p. 77), aí abrangendo-se não apenas os homens, mas como todos os demais seres vivos (animais e vegetais).

O biocentrismo de tipo igualitário, é fundado em dois pontos fundamentais: (i) a atitude de respeito pela natureza, (ii) e a perspectiva biocêntrica da natureza (LOURENÇO, 2019 , p. 83) ${ }^{15}$. Aponta sobre essa tese que, "em síntese, atribuiríamos valor moral à potencialidade de desenvolvimento biológico natural de organismos vivos. Agir contra a realização dessa potencialidade seria agir contra o bem próprio perseguido por esse mesmo ente" (LOURENÇO, 2019, p. 86).

Já o biocentrismo não igualitário é tratado por autores que "projetam valores próprios com graus distintos a depender da riqueza e complexidade de cada organizamos vivo (quanto maior a complexidade, maior o valor atribuído)" (LOURENÇO, 2019, p. 106) ${ }^{16}$.

O biocentrismo mitigado (ou animalismo) seria a tese biocentrista fundada na senciência, ou seja, na capacidade e medida e respostas sensitivas por determinados animais, e que "adota a premissa de que apenas algumas espécies de seres vivos estariam habilitados à considerabilidade moral" (LOURENÇO, 2019, p. 411) ${ }^{17}$.

\footnotetext{
${ }^{14}$ Que atribui como "inflado" e com "perda de conteúdo material" (LOURENÇO, 2019, p. 73), além da similaridade com o termo "desenvolvimento sustentável" para quem "ao que tudo indica, não conseguimos mais recuperar o conceito genuíno diante de sua diluição linguística e emprego abusivo" (LOURENÇO, 2019, p. 74).

15 "Conforme foi dito, dentro dessa concepção, mesmo que o organismo em questão não possua qualquer nível de consciência que lhe permita acessar autonomamente os seus próprios interesses e demandas, como ocorre no caso de um micro-organismo ou de um vegetal, existiria um valor objetivamente acessível sujeito a apreensão pelos seres humanos" (LOURENÇO, 2019, p. 87).

16 "Varner afirma a existência de uma hierarquia de valores a partir de três princípios gerais. São eles: (p1) Em princípio, a morte de uma entidade que possui desejos é pior do que a morte de uma entidade que não possui desejos. (p2) Em princípio, a satisfação de projetos relevantes e estruturais é mais importante que a satisfação de desejos não categóricos ou secundários. (p3) Guardadas as mesmas condições, entre dois desejos situados em um mesmo patamar de hierarquia de desejos de um determinado indivíduo, é melhor satisfazer aquele desejo que requer como condição para sua satisfação a eliminação de menor quantidade de interesses de terceiros (sejam esses interesses qualificáveis como desejos ou como interesses puramente biológicos)" (VARNER, 1998, p. 7879 apud LOURENÇO, 2019, p. 106).

17 "As vidas e as experiências dos animais, individualmente considerados, possuiriam um valor moral em função da sua subjetividade (ponto de partida relacionado ao individualismo moral). A senciência, na maior parte das
} 
Por fim, a visão ecocêntrica (ou ecocentrismo) no sentido de que "as visões ecocêntricas tomam um ponto de partida bastante diverso das provenientes do biocentrismo ao adotarem o holismo como concepção metafísica que valoriza a integridade das coletividades naturais (por exemplo, espécies, ecossistemas, processos naturais e a própria biosfera como um todo)" (LOURENÇO, 2019, p. 412).

Assim, organizadas tais correntes éticas, o autor começa a discorrer no sentido de buscar uma conclusão a apresentar. Inicia assim o fechamento, ao destacar a necessidade de se enfatizar uma ética ambiental "antiantropocêntrica" com fincas a buscar a importância das dimensões naturais não humanas.

\begin{abstract}
A ética verdadeiramente ambiental é antiantropocêntrica, no sentido de afirmar a considerabilidade moral da dimensão não humana. Ela indica que o valor da dimensão não humana não se reduz à sua utilidade e não seria, nesse sentido, meramente relacional. As grandes perguntas da ética aplicada ao meio ambiente, além do preenchimento dos seus requisitos lógicos internos (exigências formais de consistência, não vacuidade e decidibilidade), dizem respeito a investigar a estrutura da alteridade, no sentido de desvelar quem são os outros e qual é o seu valor (intrínseco ou instrumental). O grau da importância moral (estatuto moral) determinará o surgimento de obrigações morais diretas para esses entes (LOURENÇO, 2019, p. 410).
\end{abstract}

Em sequência, apresenta pontos positivos e negativos acerca das linhas alternativas à proposta tradicional antropocêntrica, ressaltando, novamente, que o biocentrismo e o ecocentrismo são projetos éticos desconectados da importância e foco único no ser humano e que, por isso, tendem a ser propostas mais evoluídas no contexto atual de busca de nova teoria fundante à ética ambiental, ressaltando que "o assoalho moral é a própria vida" (LOURENÇO, 2010, p. 410).

Acredita, portanto, que a importância ao valor individual dos seres é que conduz à sua conclusão para o reconhecimento da dimensão centrada no valor dos animais no caminho ético a ser seguido. Mesmo com ressalvas à senciência, afirma que com tal valoração da relação homem-animal a um patamar de igualdade concreta (formal, horizontal e fundamental), estaria dado o efetivo passo de mudança paradigmática:

vezes, é o critério utilizado para demarcar a inclusão na comunidade moral (condição necessária para a considerabilidade moral). Os animais sencientes contam moralmente (embora exista um debate sobre onde traçar a linha que separa os sencientes de não sencientes, é razoável afirmar que ao menos os vertebrados e algumas espécies de invertebrados preencheriam os requisitos da senciência)" (LOURENÇO, 2019, p. 411). 
A premissa de que os animais possuem uma existência subjetiva e são sujeitos morais, ou seja, de que são os alvos de obrigações morais diretas e que possuem direitos fundamentais em princípios invioláveis, consubstancia uma visão robusta do valor intrínseco para além da humanidade e traduz implicações de ordem pratica que exigem alterações comportamentais significativas (com imposição de obrigações negativas e positivas) que, em última análise, beneficiarão não só os animais, mas também toda a natureza (LOURENÇO, 2019, p. 412-413).

$\mathrm{Na}$ verdade, rumo à concretude e efetividade prática dos conceitos de proteção à natureza, o autor caminha no sentido de que, a par da teoria "escolhida", fundamental é sua reflexão e aplicação em uma nova visão sistêmica ecológica.

Essa narrativa ou fio condutor da "ética ambiental" (assim como o foi com os estudos da bioética), indica a substituição da importância máxima ou única do homem, pelos demais entes, seres e todo o sistema ecológico, numa linha horizontal. Ou seja, ratifica a reflexão de que o debate ético atual não pode pressupor da integração dos seres não humanos no seu bojo de importância.

É a máxima que sustenta este estudo, que propõe uma evolução do pensamento kantiano (agora na proposta em prol da dignidade de todos os seres), e que é o ponto de inflexão entre Lourenço (2019) e Naves e Reis (2019).

\section{A ETICIDADE AMBIENTAL COMO A ÉTICA DO LEGISLADOR UNIVERSAL}

Demonstrada a importância da filosofia kantiana para a dignidade da pessoa humana como premissa primeira da ciência social e jurídica, e a necessidade de uma mudança do paradigma estritamente focado no ser humano como epicentro do direito, surge a eticidade ambiental como uma nova linha de pensamento de forma a trazer reflexão sobre o patamar de importância, ou mesmo sobre o novo ou papel do ser humano no planeta.

O desrespeito histórico ao ser humano enquanto pessoa, e sua desvalorização enquanto ser vivente digno de direitos - tendo-se como marco a Segunda Grande Guerra com todos os abusos e delírios político militares que vitimaram milhões de pessoas ${ }^{18}$ - foram episódios que exigiram das ciências sociais uma forte mudança em sua base filosófica, alcançando-se, como dito, a era da dignidade da pessoa humana como vetor de todas as condutas, leis, princípios e estudos:

\footnotetext{
${ }^{18}$ Como aqui se elege agora atualmente - até mesmo de maneira alerta e preventiva - as mudanças climáticas e a pandemia como marcos e fundamentos para a mudança da estrutura jurídico-científica.
} 


\begin{abstract}
Na reconstrução de um mundo moralmente devastado pelo totalitarismo e pelo genocídio, a dignidade humana foi incorporada ao discurso político dos vitoriosos como uma das bases para uma longamente aguardada era de paz, democracia e proteção dos direitos humanos. A dignidade humana foi então importada para o discurso jurídico devido a dois fatores principais. $\mathrm{O}$ primeiro deles foi a inclusão em diferentes tratados e documentos internacionais, bem como em diversas constituições nacionais, de referências textuais à dignidade humana. $\mathrm{O}$ segundo fator corresponde a um fenômeno mais sutil, que se tornou mais visível com o passar do tempo: a ascensão de uma cultura jurídica pós-positivista, que reaproximou o direito da moral e da filosofia política, atenuando a separação radical imposta pelo positivismo pré-Segunda Guerra (BARROSO, 2016, p. 18-19).
\end{abstract}

No entanto, a preocupação hodierna - e também futura - é outra. Não em substituição à dignidade humana. A luta dos pesquisadores e operadores em prol da justiça humana continua. É da essência da coisa, é visceral à ética, à justiça e ao direito, a procura pela sustentação da causa humana, mas, agora, com o viés de efetiva sustentabilidade dos demais seres e do entorno natural, a partir de suas múltiplas dimensões ${ }^{19}$.

O alerta real e efetivo é de que a humanidade pode assistir a uma série de eventos globais (frisa-se, infelizmente, a pandemia e os incêndios), que faz a preocupação desfocar do homem e se voltar para a natureza. Não em permuta, como dito, mas em acréscimo, em ajuda, em compartilhamento de preocupação e foco.

O mesmo homem que precisou de suporte teórico, é aquele que vem contribuindo para o desmonte de sua própria casa planetária. Daí a necessidade premente de mudança paradigmática, fazendo o homem justificar o seu papel de "ser" humano ${ }^{20}$ para, de fato, conjugar os seus interesses em obediência constante à proteção ecológica. Nesse ponto, assevera Harari (2018):

No século XXI, o desafio apresentado ao gênero humano pela tecnologia da informação e pela biotecnologia é indubitavelmente muito maior do que o desafio que representaram, em época anterior, os motores a vapor, as ferrovias e a eletricidade. E, considerando o imenso poder destrutivo de nossa civilização, não podemos mais nos dar ao luxo de ter mais modelos fracassados, guerras mundiais e revoluções sangrentas. Desta vez, os modelos fracassados podem resultar em guerras nucleares, monstruosidades geradas pela engenharia genética e um colapso completo da biosfera. Portanto, temos de fazer melhor do que fizemos ao enfrentar a Revolução Industrial (HARARI, 2018, p. 58).

\footnotetext{
${ }^{19}$ Para aprofundamentos nas dimensões da sustentabilidade, ver: FREITAS, 2016; GOMES; FERREIRA, 2017, p. 93-111 e GOMES; FERREIRA, 2018, p. 155-178.

20 "O homem é uma corda estendida entre o animal e o Além-homem: uma corda sobre um abismo, perigoso seguir esse caminho, perigoso olhar para trás, perigoso temer e parar. A grandeza do homem consiste em ser uma ponte e não uma meta; o que se pode amar no homem, é ser ele uma ascensão e um declínio" (NIETZSCHE, 2011, p. 16).
} 
Isso tudo no destaque à passagem humana pelo planeta, inclusive com a indicação do Antropoceno como uma nova Época ou tempo geológico ${ }^{21}$, mesmo que ainda não oficialmente demarcada $^{22}$, o que atesta o impacto das atividades humanas no globo, alcançando-se o seu limite de exploração e desequilíbrio. Dessa forma, Veiga é capaz de explicar com clareza:

Definir uma nova Época, em que a humanidade teria se tornado o vetor mais determinante da evolução ecossistêmica, permanece assunto controverso, como já foi destacado acima. Mas ninguém tem o direito de ignorar que, ao menos desde meados do século XX, os humanos passaram a exercer pressões excessivas sobre alguns dos mais relevantes ciclos biogeoquímicos, como os do carbono e do nitrogênio. Ao mesmo tempo em que ocorria inédita escalada geral de outros impactos artificiais (antrópicos) sobre a biosfera. Talvez baste lembrar que, de todo o dióxido de carbono atribuível às atividades humanas hoje estocado na atmosfera, três quartos foram emitidos apenas no curto lapso dos últimos setenta anos. No piscar de olhos histórico em que viveram as três últimas gerações, o número de veículos motorizados passou de 40 milhões para 850 milhões. A produção de plásticos, de mero milhão de toneladas para 350 milhões de toneladas. A quantidade de nitrogênio sintético (principalmente para fertilização agrícola) foi de 4 milhões de toneladas para mais de 85 milhões de toneladas. Somados à erosão da biodiversidade e à acidificação dos oceanos, esses rapidíssimos saltos caracterizam o que está sendo cada vez mais entendido como a "Grande Aceleração" (VEIGA, 2019, p. 27).

Outros autores que pesquisam o tema das mudanças climáticas e problemas ecológicos globais, como Diamond (2020), que atenta para o "Colapso" e Lovelock (2010) que, novamente, soa o "Alerta final”, bem como Wallace-Wells (2019), apostam num futuro sombrio de uma "Terra inabitável”, todos no chamamento de atenção de necessidade de novas providências para a comunidade humana universal, caso não ocorram mudanças nas atitudes da economia, hábitos e consumo. É uma nova base que se forma e se apresenta, exigindo da pesquisa jurídica algumas respostas e/ou tentativas de adequação ao que clama o planeta Terra. Para Azevedo e Clark:

\footnotetext{
21 "A Geologia costuma usar maiúsculas em "Era", "Época" e "Idade”, noções que para essa disciplina não são intercambiáveis, ao contrário do que ocorre com a História. No âmbito das humanidades, se diz, sem risco de erro, "época industrial", "era industrial" ou "idade industrial". Não é assim na Geologia, ciência para a qual é erro crasso confundir Época com Era, pois cada Era é composta de várias Épocas. Mesmo assim, é bem frequente que comunicadores deem preferência ao termo "era" (com minúscula) para Antropoceno ou Holoceno" (VEIGA, 2019, p. 11).

22 "O $35^{\circ}$ Congresso Internacional de Geologia, realizado entre o fim de agosto e o início de setembro de 2016, na Cidade do Cabo, África do Sul, estevem bem longe de acatá-la. Frustrou as expectativas dos que supunham que a discussão seria mais sobre as diversas datas para o início da nova Época. Em direção diametralmente oposta, esse conclave recusou decretar o fim do Holoceno.[...]Por enquanto, essa turma não conseguiu convencer a Comissão Internacional sobre Estratigrafia (ICS), composta de dezesseis subcomissões, cada uma com vinte votos, e dirigida por um comitê executivo de apenas três pesquisadores. Então, oficialmente, não estamos no Antropoceno" (VEIGA, 2019, p. 29).
} 
Por sua vez, a integração da sustentabilidade ao conceito de desenvolvimento está pautada pela construção de um novo paradigma social. O avanço científico pode propiciar tecnologias e ferramentas destinados a compatibilidade dos sistemas produtivos, distribuição social de bens e serviços e preservação/regate da natureza. E, portanto, virando as páginas das destruições e injustiças do crescimento modernizante (AZEVEDO; CLARK, 2019, p.85).

A partir daí a conexão com a filosofia de Kant - e seu imperativo categórico - merece releitura, estudo e ampliação, fomentados pela nova eticidade ambiental de matriz de proteção ecológica, como corrobora Jonas:

O imperativo categórico de Kant dizia: 'Aja de modo que tu também possas querer que tua máxima se torne lei geral' [...] para um imperativo mais condizente ao novo tipo do agir humano: 'Aja de modo a que os efeitos de tua ação sejam compatíveis com a permanência de uma autêntica vida humana sobre a Terra'; ou expresso negativamente 'Aja de modo que os efeitos de tua ação não sejam destrutivos para a possibilidade futura de uma tal vida'; ou simplesmente: 'não ponha em perigo as condições necessárias para a conservação indefinida da humanidade sobre a Terra'; ou, em um uso novamente positivo: 'inclua na tua escolha presente a futura integridade do homem como um dos objetos do teu querer.' (JONAS, 2006, p. 4748).

Portanto, uma nova eticidade ambiental como sendo a ética do legislador universal é premente e necessária para que os esforços teóricos e as ações práticas possam, efetivamente, girar a chave de leitura da preocupação humana para a proteção ecológica, como bem delineado por Bosselman:

Para se tornar um conceito verdadeiramente ecológico, a justiça precisa chegar ao mundo não humano. Como veremos o "elo perdido", tanto no debate sobre o desenvolvimento sustentável como no debate da justiça é o reconhecimento da integridade ecológica. Não é o suficiente cuidar dos seres humanos que vive hoje e amanhã, quando os processos naturais que sustentam a vida estão em risco (BOSSELMAN, 2016, p. 129) ${ }^{23}$.

Ao laborar em face do cuidado com o planeta e com a proteção ecológica, o homem se torna ainda mais especial e efetivo do que o foi como em seu contorno dado por Kant.

\section{CONSIDERAÇÕES FINAIS}

\footnotetext{
${ }^{23}$ Tradução livre de: "To become a truly ecological concept, justice needs to reach out into the non-human world. As we will see the "missing link", both in the debate on sustainable development and in the justice debate is the recognition of ecological integrity. It is not enough to care for human living today and those living tomorrow, when the natural processes that sustain life are at risk" (BOSSELMAN, 2016, p. 129).
} 
Ao final desse estudo é possível arrematar que fica reforçada a eticidade ambiental como um novo modelo de ética a guiar os pesquisadores e aplicadores jurídicos em uma chave de leitura que passe a destacar a proteção ecológica como escopo mor.

Nesse sentido, é vital que o papel do ser humano como personagem principal da filosofia e do Direito deve ser reconfigurado para que a proteção ecológica fique no seu lado no grau de importância, pesquisas e ações efetivas, em nova premissa para a atitude humana na Terra.

Nessa trilha, foi observada a importância da filosofia kantiana para o reforço da dignidade da pessoa humana como princípio fundamental jurídico e social, com a demonstração de seu Imperativo Categórico como símbolo da racionalidade e vontade humanas como motores da ética e do direito, principalmente na era moderna.

Adiante, com base nas obras de Naves e Reis (2019) e Lourenço (2019) foram apresentadas as principais correntes filosófico-ambientais que discutem os desafios e ideias para que um novo sustentáculo teórico seja apresentado como alternativa a um pensamento meramente focado no homem.

Nesse sentido, também foram citadas as ideias do ecocentrismo, a perspectiva holística, a revolução ecojurídica e a justiça ecológica ${ }^{24}$.

Dessa forma, importante ressaltar que não haverá a troca do patamar de importância da dignidade, ou mesmo de se subjugar o cuidado com o ser humano em face da ecologia. É justamente no sentido de se tornar ainda mais racional e humano o "ser" homem, ao fazê-lo entender que a sua morada (Terra) merece os cuidados (filosóficos, científicos e jurídicos) que ele mesmo já possui, pelo menos teoricamente.

Como dito, é fundamental compreender que a ideologia de uma nova razão humana deve considerar e integrar a natureza nos seus objetivos e ações, em uma nova missão que abranja, necessariamente, a proteção à natureza.

O presente estudo conclui, assim, que a importância da filosofia kantiana para a dignidade da pessoa humana como primeira premissa da ciência social e jurídica foi fundamental, mas há necessidade de uma mudança do paradigma estritamente focado no ser humano como epicentro do Direito, o que faz pensar a eticidade ambiental como uma nova

\footnotetext{
${ }^{24}$ Para aprofundamentos, ver: CAPRA; MATTEI, 2018.
} 
linha de reflexão e parâmetro a trazer estudos sobre o novo ou papel do ser humano, não mais isolado no pódio da atenção da filosofia e ciência, especialmente jurídicas.

É pertinente considerar que se torna fundamental a mudança filosófica e jurídica que refaz o papel do homem na história da humanidade não mais como "fim" sozinho e isolado, mas com escopo fundamental de ser "meio" e figura efetivamente integrante na participação de nova missão de proteção ecológica.

\section{REFERÊNCIAS}

AZEVEDO, Marcelo Tobias da Silva; CLARK, Giovani. Direito ao desenvolvimento: reflexões a partir do direito econômico sobre o desenvolvimento sustentável. Revista Direito e Desenvolvimento, João Pessoa, v. 10, n. 2, p. 72-87, jul./dez. 2019. Disponível em: https://periodicos.unipe.br/index.php/direitoedesenvolvimento/issue/view/48. Acesso em: 25 nov. 2020.

BARROSO, Luís Roberto. A dignidade da pessoa humana no direito constitucional contemporâneo: a construção de um conceito à luz da jurisprudência mundial. 4. ed. Belo Horizonte: Fórum, 2016.

BOSSELMAN, Klaus. The principle of sustainability: transforming law and governance. 2.ed. Reino Unido: Routledge, 2016.

CAPRA, Fritjof; MATTEI, Ugo. A revolução ecojurídica: o direito sistêmico em sintonia com a natureza e a comunidade. São Paulo: Cultrix, 2018.

CARSON, Rachel. Primavera silenciosa. São Paulo: Gaia, 2011.

COELHO, Saulo de Oliveira Pinto; MELlO, Rodrigo Antônio Calixto. A sustentabilidade como um direito fundamental: a concretização da dignidade da pessoa humana e a interdisciplinaridade do direito. Revista Veredas do Direito, Belo Horizonte, v. 8, n. 15, p. 09-24, jan./jun. 2011. Disponível em: http://revista.domhelder.edu.br/index.ph p/veredas/article/view/208. Acesso em: 03 ago. 2020.

CUNHA, Clarissa de Oliveira Gomes Marques da; AFONSO, Henrique Weuil. Rumo a futuros distópicos? História do direito, pós-colonidade e crítica no Antropoceno. Revista Veredas do Direito, Belo Horizonte, v. 14, $\mathrm{n}^{\circ}$ 30, p. 187-213, dez. 2017. Disponível em: http:domhelder.edu.br/revista/index.php/veredas/article/view/1048/711. Acesso em: 27 jan. 2019.

DIAMOND, Jared M. Colapso. 12. ed. Tradução de Alexandre Raposo. Rio de Janeiro: Record, 2020.

FREITAS, Juarez. Sustentabilidade direito ao futuro. 3. ed. Belo Horizonte: Fórum, 2016. 
GOMES, Magno Federici; FERREIRA, Leandro José. A dimensão jurídico-política da sustentabilidade e o direito fundamental à razoável duração do procedimento. Revista do Direito, Santa Cruz do Sul, n. 52, v. 2, p. 93-111, maio/set. 2017. Disponível em: http://dx.doi.org/10.17058/rdunisc.v2i52.8864. Acesso em: 20 ago. 2018.

GOMES, Magno Federici; FERREIRA, Leandro José. Políticas Públicas e os objetivos do desenvolvimento sustentável. Revista Direito e Desenvolvimento, João Pessoa, v. 9, $\mathrm{n}^{\mathrm{o}}$ 2, p. 155-178, ago./dez. 2018. Disponível em: https://doi.org/10.25246/direitoedesenvolvimento.v9i2.667. Acesso em: 27 out. 2019.

HARARI, Yuval Noah. 21 lições para o século 21. São Paulo: Companhia das Letras, 2018.

JONAS, Hans. O princípio da responsabilidade: ensaio de uma ética para a civilização tecnológica. Rio de Janeiro: PUC Rio/Contraponto, 2006.

KANT, Immanuel. Fundamentação da Metafísica dos Costumes. Tradução de Paulo Quintela. Lisboa: Edições 70 Ltda, 2011.

KRENAK, Ailton. Ideias para adiar o fim do mundo. São Paulo: Companhia das Letras, 2019.

LOURENÇO, Daniel Braga. Qual o valor da natureza? Uma introdução à ética ambiental. São Paulo: Elefante: 2019.

LOVELOCK, James. Gaia: alerta final. Rio de Janeiro: Intrínseca, 2010.

NAVES, Bruno Torquato de Oliveira; REIS, Émilien Vilas Boas. Bioética ambiental: premissas para o diálogo entre a ética, a bioética, o biodireito e o direito ambiental. 2.ed. Rio de Janeiro: Lumen Juris, 2019.

NIETZSCHE, Friedrich. Assim falava Zaratustra: um livro para todos e para ninguém. Tradução de Mário Ferreira Santos. Petrópolis: Vozes, 2011.

TAYLOR, Paul. Respect of nature: a theory of environmental ethics. Princeton, NJ: Princeton University Press, 2011.

VEIGA, José Eli da. O antropoceno e a ciência do sistema Terra. São Paulo: Editora 34, 2019. 